\title{
THE EFFECT OF WATER MIST COOLING OF CASTING DIE ON THE SOLIDIFICATION, MICROSTRUCTURE AND PROPERTIES OF AISi20 ALLOY
}

\begin{abstract}
Unmodified AlSi20 alloy were casted at the research station, allowing for sequential multipoint cooling using a dedicated computer-controlled program. This method allows for the formation of the microstructure of hypereutectic AlSi20 alloy and also increases hardness. Primary silicon dendrites were found in the microstructure of cooled samples. Based on these dendrites, the formation of primary silicon particles is explained. Cooling of casting die with a water mist stream causes changes in solidification, which leads to expansion of the boundary layer with columnar crystals and shrinkage of the core zone with equiaxed crystals. It also causes more regular hardness distribution around pre-eutectic Si crystals, which can lead to tensile strength and machinability improvement.

Keywords: silicon dendrites, casting die cooling, water mist, hypereutectic Al-Si alloy
\end{abstract}

\section{Introduction}

The use of water mist cooling of die can increase the efficiency of aluminium alloys [1]. Władysiak (2013) investigated the effect of water mist cooling on the properties of hypoeutectic AlSi7Mg alloy and also indicated optimal process parameters.

Yamagata et al. (2008) reviewed the positive influence of intensive die cooling, resulting in the rapid solidification of mechanical properties and the quality of castings. Heat transfer efficiency causes a reduction in the primary $\mathrm{Si}$ particle size and a decrease in secondary dendrite arm spacing as reported by Shabestari and Malekan (2005). The equivalent diameter of the primary Si decreased from $89.7 \pm 17.3$ to $16.5 \pm 3.8 \mu \mathrm{m}$ and the SDAS from $22.1 \pm 5.9$ to $5.1 \pm 0.8 \mu \mathrm{m}$, with an increase in the cooling rate from 4.9 to $82.9 \mathrm{~K} / \mathrm{s}$. In science and industry, various methods are available for die cooling and these are used particularly in high pressure die casting technology. One of these methods uses pressured air. Shen and Lü (2014) investigated the efficiency of this technology and its influence on castings. Unfortunately, this method does not make possible heat flux higher than $782 \mathrm{~W}$, as pointed out by Władysiak (2010). The other approach is to use running water or another type of coolant in the channels or pipes installed inside the die as described in Cho and Kim (2014). The effect of doing this is significant. Increasing the cooling rate caused a reduction in the primary Si particle size and a decrease in second dendrite arm spacing. This method can provide a cooling rate of $110 \mathrm{~K} / \mathrm{s}$ in HPDC and is therefore extremely efficient. Hejazi et al. (2010) achieved cooling rate of $292 \mathrm{~K} / \mathrm{s}$ using a copper mold and the significant increase in hardness of the casting was observed. There are also investigations that have combined cooling channels with an electric heating system inside in order to increase the temperature of the die before casting [9]. The drawbacks of these solutions are high coolant consumption, despite the process running in a closed circuit, the high cost of implementing such a system in die and the small range for controlling the cooling rate. In cited research, CR was regulated only by the thickness of casting. Additionally, there is no possibility for easily achieving CR diversity in the different parts of the casting or to eventually change it during the casting process after the die has been produced.

In the literature, we found one investigation that used water mist cooling, but it was used to directly cool the casting. Nowak et al. (2013) applied the system of "water spray nozzles" in the continuous casting of extruded profiles. Quenching improved the mechanical properties, despite being applied after the solidification process, which was done so as not to influence the creation of pre-eutectic Si particles.

Kang et al. (2015) investigated the post solidification intensive riser cooling method (PSIRC). Risers are cooled by forced air or water mist from its top surface at the moment that the solidification of a casting is finished. The risers are then turned into cooling passages during the cooling process of a casting, in contrast to their function of feeding passages during the solidification process. Again, for this method, cooling starts once solidification has finished. The strength and hardness at the bottom of the riser were improved; meanwhile, its residual stress was greatly reduced.

In this research the cooling undergoes via the evaporation of water droplets on the hot surface of the casting die during the

\footnotetext{
* LODZ UNIVERSITY OF TECHNOLOGY, DEPARTMENT OF MATERIALS ENGINEERING AND PRODUCTION SYSTEMS, 1/15 STEFANOWSKIEGO STR., 90-924 LODZ, POLAND

* Corresponding author: arturkozun@gmail.com
} 
solidification process. An analysis of earlier studies indicates that the cooling of mould with the water mist stream is more efficient than cooling with other mediums. This approach enables the shaping of microstructures and achieving high quality casts made of neareutectic silumins with improved properties. This means that the positive effect of this method is similar to the effect of using alloying additives, which is already a well-known method for improving alloy properties as reviewed by Rapiejko et al. (2014). Heusler and Schneider (2002) investigated the influence of alloying elements on the eutectic temperature and the eutectic depression as essential thing for assessing the quality of a modification treatment by means of thermal analysis. There are other low-cost methods for improving castings quality and mechanical properties, such as the tilting position of mould during pouring or applying vibrations [14]. No other method has as many advantages as cooling die with water mist.

The efficiency of the heat transfer process is largely determined by the characteristics of the generated stream, optimization of the amount of air and water in the mist stream and the adequate spraying of water.

The aim of the study was to investigate the effect of water mist cooling on a microstructure, hardness and the way in which solidification of hypereutectic Al-Si alloy takes place. Castings made of these Al-Si alloys are used for heavy-duty pistons in combustion engines. They have good casting properties, corrosion resistance, good mechanical properties at elevated temperatures, abrasion resistance and a low coefficient of abrasion and thermal expansion.

\section{Experimental}

The study was conducted on a working station (shown in Fig. 1) using the mould presented in Fig. 2. The water mist was produced in the device $(1,2)$, which dosed the appropriate amount of water and its dispersion in the air by centrifugal spraying of water in a stream of compressed air (3). Previous work by the author proved that the highest heat flux can be achieved by applying water pressure of $0.35 \mathrm{MPa}$ and air pressure of $0.3 \mathrm{MPA}$, and water and air proportions of $0.156 \mathrm{1} / \mathrm{min}$ and $350 \mathrm{l} / \mathrm{min}$, respectively [6]. Xu et al. (2014) conducted extremely precise research about the influence of air pressure on heat flux in hot aluminium surface quenching and found that in various ranges of temperature, heat flux appears to be different; as such, it also requires various parameters of water mist for each range to achieve best efficiency. Further investigation will aim to create a system of changeable water mist parameters during the cooling process.

The mould was cooled with cylindrical nozzles placed perpendicular to the mould surface. The research mould (Fig. 2) was made of X38CrMoV51 (10) steel. The thickness of the mould wall was $4 \mathrm{~mm}$. The initial temperature of the mould was $175^{\circ} \mathrm{C} \pm 25^{\circ} \mathrm{C}$. It was heated by a gas jet before each casting. In the body of the mould, three symmetrical cooling nozzle sections were installed. Nozzles were arranged so that each nozzle section of the mould cooled one zone of the casting. The length of the nozzles was $330 \mathrm{~mm}$. The internal diameter of the nozzles was $4 \mathrm{~mm}$ and the external diameter was $6 \mathrm{~mm}$.

The control of cooling nozzles was carried out using computerized control system cooling developed by Z-Tech. The software system includes a set of functions and procedures for monitoring and controlling the process of generating a multicircuited water mist cooling system using a pre-drafted program. The mist was applied automatically at the moment when the thermal couple detected liquid metal. The thermal couple was placed inside the mould, in its central are, as indicated in Fig. 2. The water mist cooling was removed after $60 \mathrm{~s}$. The distance of the nozzle to the mould's wall surface was $13 \mathrm{~mm}$. The action area of the mist from the nozzles was limited to an open region.

The test pieces were cast in the mould at a diameter of $10 \mathrm{~mm}$ in the central area and $12 \mathrm{~mm}$ in the upper and lower areas. The length of the test pieces was $178 \mathrm{~mm}$. Synthetic hypereutectic silumin AlSi20 was used - the chemical composition is shown in Table 1. The shape of the specimen was determined by the type of mould used in this experiment which was the mould traditionally used in tensile strength tests.

The cooling effect on the resulting microstructure was evaluated using a Nikon MA200 microscope. Hardness was measured by microindentation using a HV-1000B Tester set to the norm of ISO-6507-2.

The temperature during solidification was measured using the thermocouple placed inside the casting die.

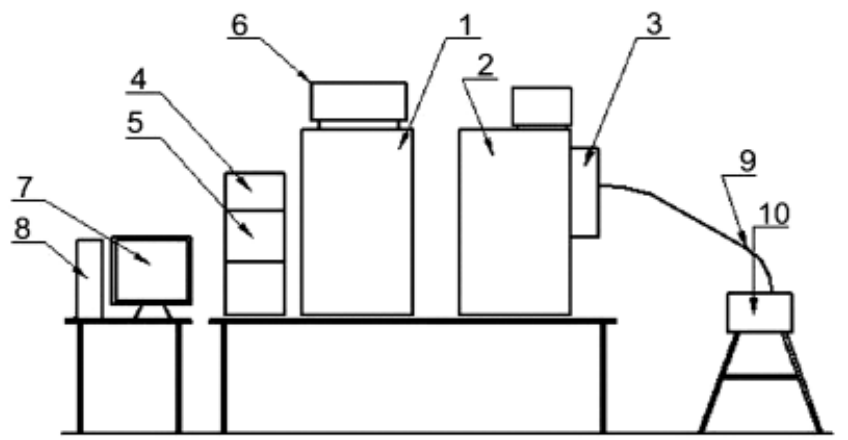

Fig. 1. A scheme of the research station: modules: 1,2-air and water dosing; 3 - mixing of components; 4, 5 - supplying of air and water solenoid valves; 6 - computer-controlled cooling; 7, 8-PC; 9 - cooling circuit; 10 - research chill

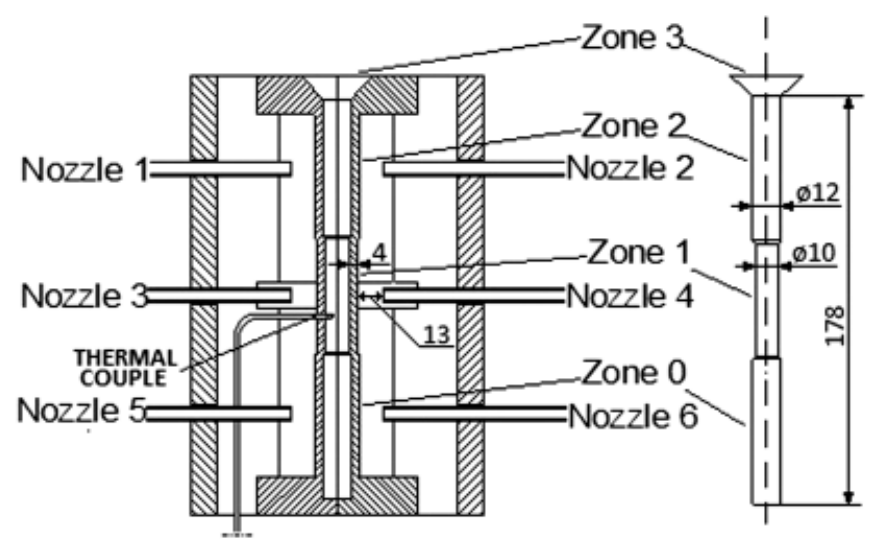

Fig. 2. Research mould, casting zones and nozzles 
TABLE 1

Chemical composition of the researched Al-Si alloy

\begin{tabular}{|c|c|c|c|c|c|c|c|c|c|}
\hline \multirow{2}{*}{ Name } & \multicolumn{10}{|c|}{ Elements, weight \% } \\
\cline { 2 - 10 } & $\mathbf{S i}$ & $\mathbf{M g}$ & $\mathbf{C u}$ & $\mathbf{M n}$ & $\mathbf{F e}$ & $\mathbf{T i}$ & $\mathbf{P}$ & $\mathbf{B}$ & Sr \\
\hline A1Si20 & 21.48 & 0.008 & 0.004 & 0.001 & 0.22 & 0.0036 & 0.0018 & 0.0062 & 0.0001 \\
\hline
\end{tabular}

\section{Results and discussion}

In this paper, the following aspects are presented:

- layered solidification and expansion of the boundary layer as the result of rapid cooling

- $\quad$ specific microstructure caused by water mist cooling of die

- $\quad$ hardness alongside the diameter of the probe and around equiaxed crystals

\subsection{Change in solidification}

The temperature was measured in the cast during solidification; temperature is shown in Fig. 3.
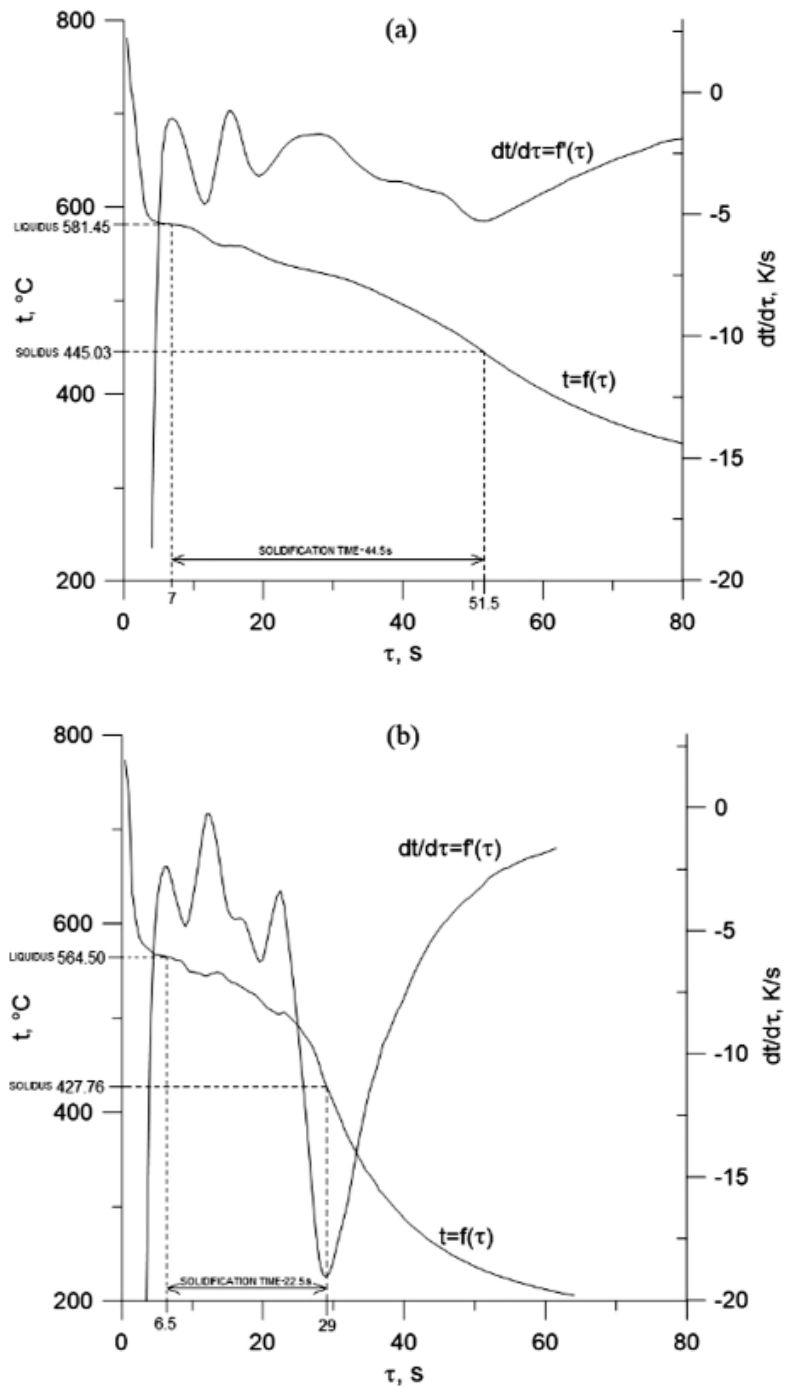

Fig. 3. Temperature obtained for the casting core: a) without cooling; b) with water mist cooling system
Water mist cooling of the casting die caused a decrease in solidification time by nearly $50 \%$. Solidification rate increased from $2.953 \mathrm{~K} / \mathrm{s}$ to $6.678 \mathrm{~K} / \mathrm{s}$, i.e., by $126 \%$. Liquidus and solidus temperatures decreased by $16.95 \mathrm{~K}$ and $17.27 \mathrm{~K}$, respectively. Liquidus and solidus temperatures were determined based on the derivative curves from Fig. 3. Table 2 shows solidification parameters comparison.

TABLE 2

Solidification parameters comparison

\begin{tabular}{|l|c|c|c|}
\hline \hline & $\begin{array}{c}\text { Without water } \\
\text { mist cooling }\end{array}$ & $\begin{array}{c}\text { With water } \\
\text { mist cooling }\end{array}$ & Unit \\
\hline Solidification time & 44.5 & 22.5 & $\mathrm{~s}$ \\
\hline Solidification rate & 2.953 & 6.678 & $\mathrm{~K} / \mathrm{s}$ \\
\hline Liquid cooling rate & 12.031 & 9.906 & $\mathrm{~K} / \mathrm{s}$ \\
\hline $\begin{array}{l}\text { Cooling rate in } \\
\text { crystallization range }\end{array}$ & 3.069 & 6.092 & $\mathrm{~K} / \mathrm{s}$ \\
\hline Liquidus temperature & 581.45 & 564.50 & ${ }^{\circ} \mathrm{C}$ \\
\hline Solidus temperature & 445.03 & 427.76 & ${ }^{\circ} \mathrm{C}$ \\
\hline
\end{tabular}

In the castings, two areas of the microstructure can be observed [16]. The first is the boundary layer, which consists primarily of columnar crystals with a thick layer of small, frozen and equiaxed crystals; this is known as the chill zone. The second area is the core, which contains mainly large, equiaxed crystals. These are spherical and randomly oriented.

Simultaneous solidification dominates in the core section. This occurs in the portion of metal between the solidified and liquid parts. On both surfaces that border the solidification area, different stadiums of solidification are observed. The criterion for simultaneous solidification is that the crystallization temperature range should be much higher than the decrease in the cast temperature:

$$
\frac{\Delta T_{k}}{\delta_{1} T}>>1
$$

where $\Delta T_{k}$-is crystallization temperature range and $\delta_{1} T-$ is the decrease in temperature in the cast.

In the boundary layer, directional solidification dominates. This occurs on the surface that borders the solid and liquid phases. The criterion for directional solidification is that the crystallization temperature range should be much lower than the temperature decrease in the cast:

$$
\frac{\Delta T_{k}}{\delta_{1} T}<<1
$$

\subsection{Microstructure}

Segregation was observed in the microstructure of obtained castings, which caused a variety of cross-sectional cast microstructures between two areas: the boundary layer and the core (Fig 4). The samples were taken from the central area of the casting, very close to the thermal couple. This study shows that the use of sequential test chill cooling during crystallization and cooling caused a $34 \%$ increase in the thickness of the boundary 

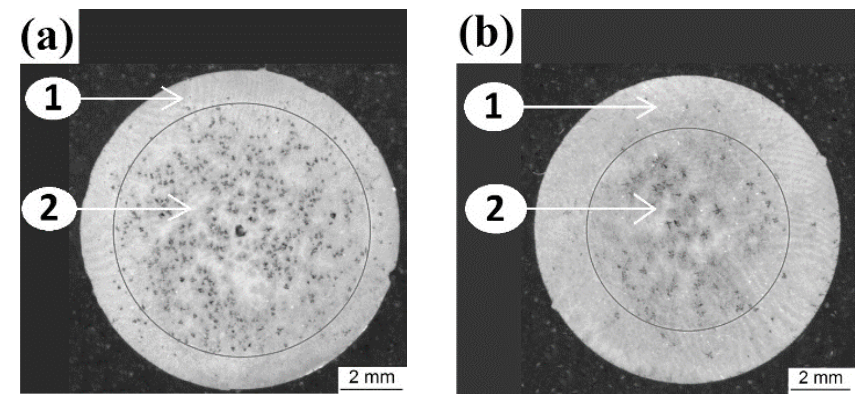

Fig. 4. Segregation of casting obtained: a) without cooling;b) with water mist cooling system method; 1 - boundary layer; 2 - cast core layer region, while reducing the diameter of the core from 8.20 to $5.38 \mathrm{~mm}$. The segregation of the core cast was observed in a concentrated form, while for uncooled casting, segregation was dispersed. The boundary layer consisted of many more pre-eutectic crystallized $\alpha$ phase dendrites than was observed in the core.

Fig. 5 illustrates segregation more precisely via panoramic images taken alongside the diameter of the probe.

Sequential spot cooling with the use of water mist allows for layered solidification, leading to an increase in the participation of directional solidification. This may improve the quality of casting, as in general, directional solidification allows for eliminating

a)

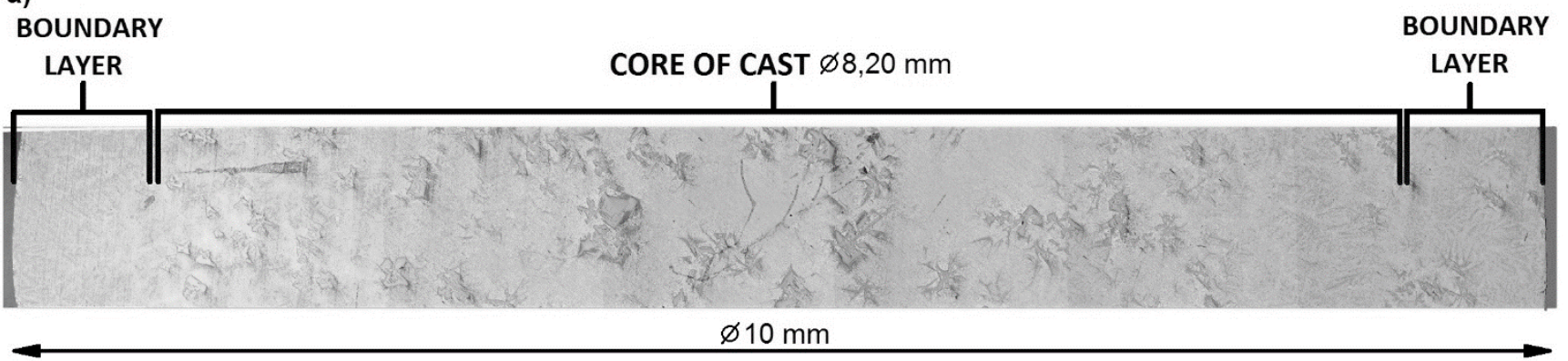

b)

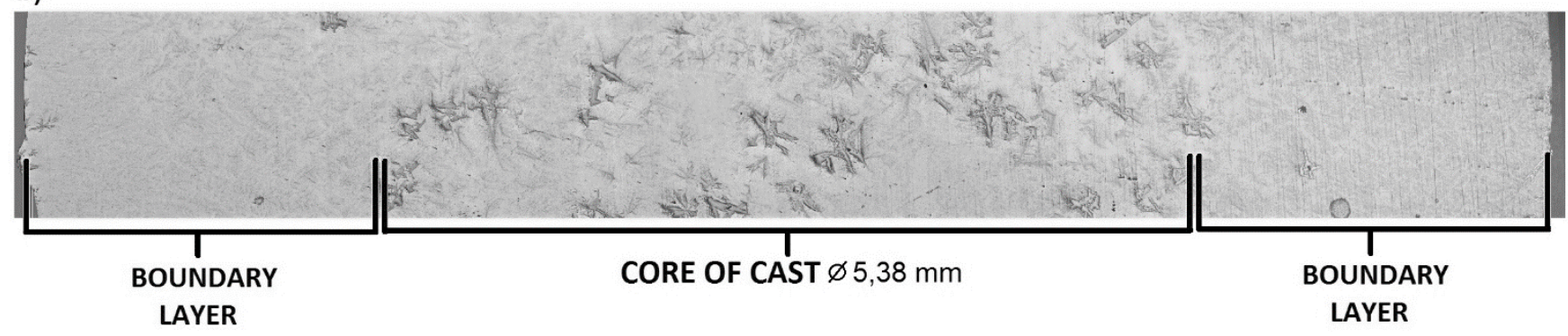

Fig. 5. Segregation of casting obtained a) without cooling; b) with water mist cooling system method

defects and reducing shrinkage porosity in castings as reported by Ghedjati et al. (2015). It also increases the homogeneity and fineness of the microstructure.

Common problems of Al-Si alloys are high friction and abrasive wear coefficients. In automotive industry these alloys are widely used to produce engine blocks and pistons. Unfortunately it demands applying of protective coatings and iron liners. Many researchers try to find correlation between various factors and wear rate. Kubiak et al. (2011) reported that initial surface roughness has big influence on friction and wear processes under fretting conditions. Lower initial roughness reduces wear rate and smooth surface delays activation of wear process. Columnar crystals showed in Fig. 6 may have positive influence on wear resistance of Al-Si alloys. Additionally thicker boundary layer means the possibility of designing bigger machining allowance and sureness that the final surface will be in the area of directional solidification. Future work of the authors will be tribological research of Al-Si alloys and water mist cooling.

The microstructure of the core of the cast made in the water mist cooled mould is characterized by pre-eutectic crystallized silicon dendrites. This microstructure is novel, as in the litera-

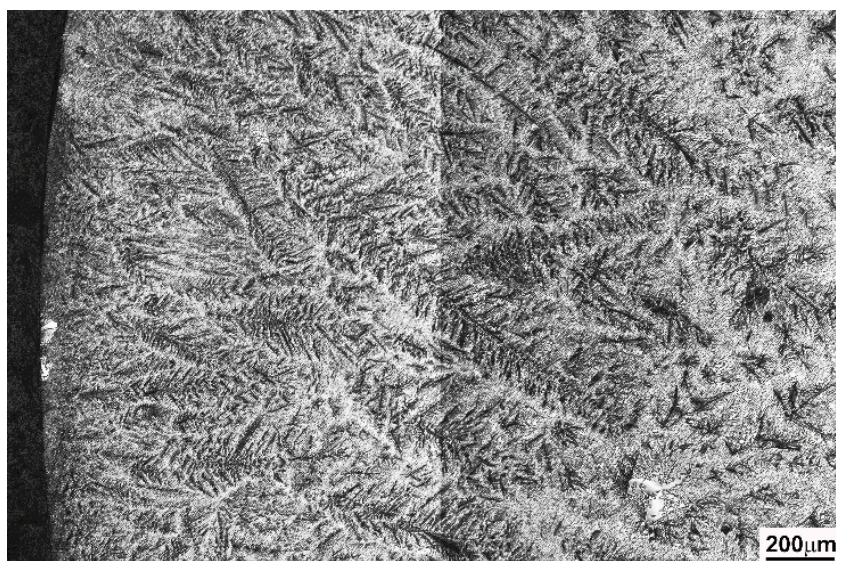

Fig. 6. Microstructure as a result of directional solidification

ture, no similar cases were found. The most common shape of primary $\mathrm{Si}$ is a brick and this appears in the majority of papers as pointed out by H Yamagata et al. (2008).

The Si dendrites were built with thick branches of the first order, which grew from the nucleus in various directions and had much thinner edge parallel branches in the second row 
(Fig. 7d-f). Many investigations of dendritic growth and its parameters in the aluminium phase have been conducted [20]. Dendrite coarsening during directional solidification of Al-CuMn alloys has been explained in detail by Chen and Kattamis (1998). It was shown that SDAS is proportional to $t^{0,43}, t$ being the local solidification time [22]. However, what was not found in any publication was an example of pre-eutectic Si dendrites. Even in rapidly solidified samples in the form of thin ribbons, which were prepared using a single roll melt spun technique and where CR could be obtained over $100 \mathrm{~K} / \mathrm{s}$, there were no such microstructures as reported by Karpe et al. (2013). A search for similar examples was also conducted in the literature for sprayformed alloys where it was possible to achieve a solidification rate in the range of $10^{2}-10^{3} \mathrm{~K} / \mathrm{s}$ as reported by Raghukiran and Kumar (2015). ZHU et al. (2014) studied crystallization process and showed the scheme of microstructure evolution of sprayformed $\mathrm{Al}-27 \% \mathrm{Si}$ alloy in semisolid state. No similar examples of the Si dendrites were found.

Lamellar, dendritic eutectic is also visible in the microstructure of the cast made in the water mist cooled mould. Dendritic eutectic grains are the dominant component of the microstructure column in the boundary layer of the casting.

Compared to the microstructure of the probe obtained without using a cooling system (Fig. 7a-c), there are no dendritic shapes in its microstructure. Sharp silicon brick shapes were dominant.

Changes in the morphology of crystallizing phases were likely the result of concentrated supercooling. This is caused by the high cooling rate of silumin, which prevents equalization of the concentration of the chemical composition in the melt. Under such conditions, there was rapid enrichment of liquid in aluminium phase $(\alpha)$, which is located in the spaces between the dendrite Si branches.

Observation of many primary silicon crystals during the present work has led to the suggestion that the growth of primary particles occurs in four stages, as suggested in Fig. 8. Stage 1 shows the Si nucleus with an irregular shape and thin branches of the first order, which grew in almost perpendicular directions. Branches in the second row are very thin and have random lengths. In stage 2 the nucleus is massive and together with
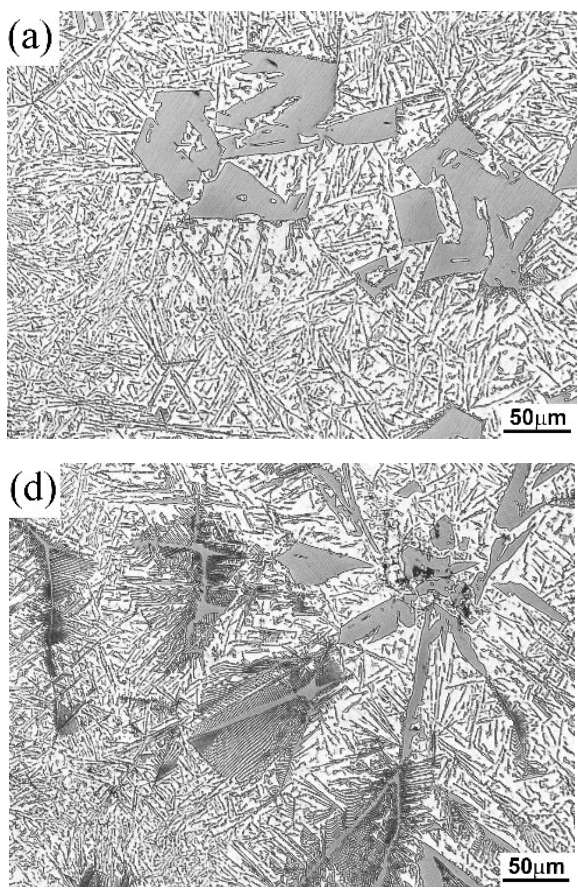
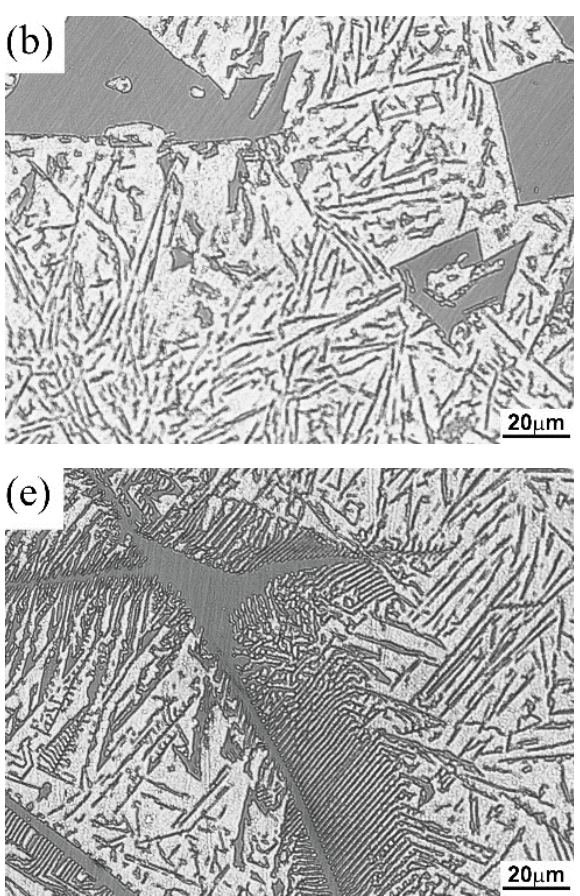
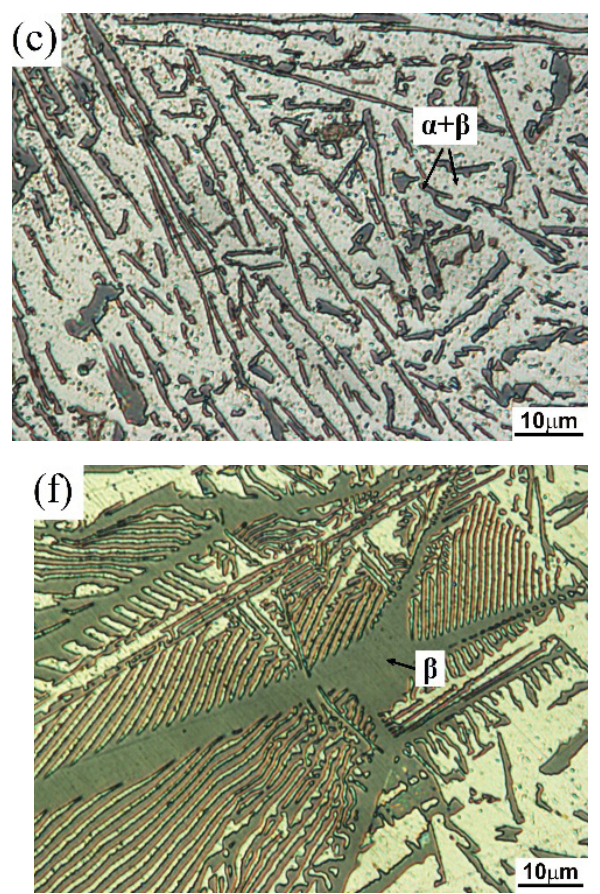

Fig. 7. Microstructure of researched Al-Si alloycasted in mould (Fig. 2) uncooled (a-c); cooled with water mist (d-f); phase $\beta$ (Si), eutectic $\alpha+\beta$ $(\mathrm{Al}+\mathrm{Si})$
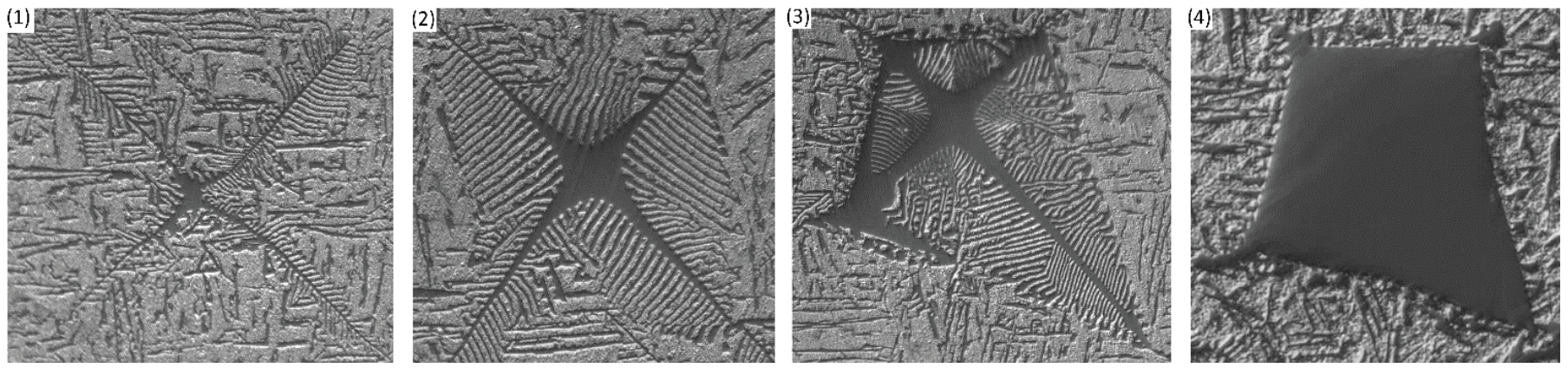

Fig. 8 . The four stages of growth of primary silicon 
significantly coarsened branches of the first order they create star-shaped particles. The branches in the second row are edge parallel and their lengths are limited to particular point. These points are arranged in a row, creating straight and visible lines. Stage 3 illustrates that the endings of the branches in the second row merge and point out the edge of final solid Si particle. Stage 4 shows solid Si particle.

The high heat flux prevented the branches coarsening and solidification of the particle as shown at stage 4 . The particles stop growing at stage 1, 2 or 3 because of supercooling. In effect they did not need as much silicon to grow as solid particle from stage 4 . This means that more silicon left in liquid and other particle had opportunity to start growing. This also suggests that the eutectic was more reached with silicon. This was proved by the hardness test.

\subsection{Hardness}

It was shown that very high CR significantly increases hardness [26]. By applying $\mathrm{CR}=104 \mathrm{~K} / \mathrm{s}$ in the solidification process, the hardness of hypereutectic alloy Al-16 wt.\% $\%$ i increased from $601.6 \pm 60.6$ to $1892.2 \pm 87.4$. Such a significant improvement can only be achieved using the melt-spinning technique. Jones (1996) searched for optimal CR above $10^{2} \mathrm{~K} / \mathrm{s}$ to achieve the highest hardness of the casting. No papers investigating the hardness of gravity die castings cooled by water mist or other low-cost methods were found. In order to prove the positive influence of the presence of columnar crystals in the boundary layer, hardness of the water mist cooled probe was measured by microindentation testing method.

Change in hardness alongside the diameter is shown in Fig. 9. The highest average HV value was observed in the core of the probe in the area of a diameter of $2.5 \mathrm{~mm}$ and an average 99.5 HV. This relatively high value was the result of a large amount of silicon primary crystals obtained in this area.HV value decreased in the direction of the edge of the probeand reached a minimum value of $80.1 \mathrm{HV}$, alongside a decrease in the presence of silicon primary crystals. HV value increased significantly in the boundary layer, from a diameter of $5 \mathrm{~mm}$ up to the edge of the probe and reached a maximum value of 96.7 HV. Higher hardness in this area may have been the result of the presence of columnar crystals. This proves the positive effect of water mist cooling on the hardness of the cast.

Additionally, hardness around equiaxed crystals and dendrites was measured in the probe for both uncooled and cooled with water mist instances. Fig. 10 represents the average values found. Around the crystals in the uncooled probe, hardness decreased from above $800 \mathrm{HV}$ to $66.8 \mathrm{HV}$ at the point around $85 \mu \mathrm{m}$ from the centre of the crystal (Fig. 10a). It then increased gradually until reaching a value of $72 \mathrm{HV}$ (Fig. 10b). These areas of lower hardness around much harder crystals may cause weakness in these areas of the material, which may degrade tensile strength.

Application of water mist cooling caused hardness around dendrites to gradually decrease from $643.9 \mathrm{HV}$ to $71.5 \mathrm{HV}$ (Fig. 10c). These conditions favour more regular tension distribution, which can possibly lead to an improvement in tensile strength.

The average hardness of the eutectic in the uncooled probe was $69.2 \mathrm{HV}$ and in the water mist cooled probe it was $85.8 \mathrm{HV}$, making it $24 \%$ greater.

\section{Conclusions}

This study indicates that the use of water mist cooling of the moulds:

- $\quad$ shortens solidification time by up to $50 \%$ for hypereutectic AlSi20 alloy,

- decreases liquidus and solidus temperatures by nearly $17 \mathrm{~K}$,

- causes the formation of pre-eutectic silicon dendrites in the microstructure of hypereutectic Al-Si alloy,

- $\quad$ the expansion of the cast boundary layer in the presence of columnar crystals by up to $34 \%$ and shrinkage to the core zone in the presence of equiaxed crystals,

- causes more regular silicon distribution in the hypereutectic Al-Si alloy,

- $\quad$ increases the hardness of the eutectic by $24 \%$,

- leads to an overall improvement in hardness of the expansion boundary layer and provides more regular hardness distribution around crystals,

- $\quad$ may improve the tensile strength and the machinability of castings.

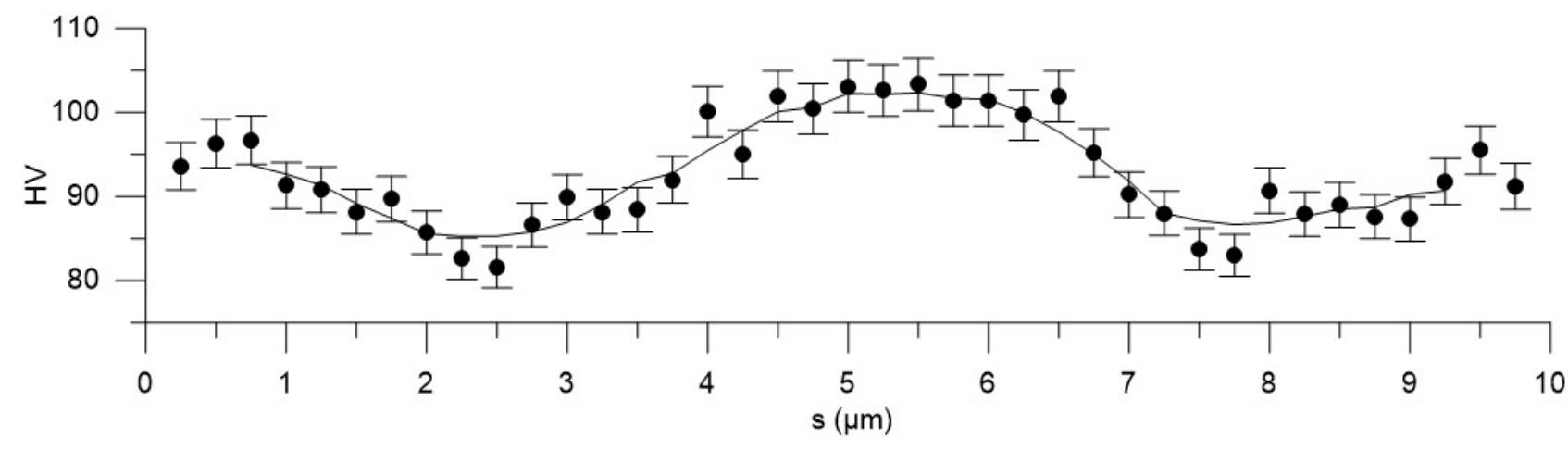

Fig. 9. Hardness alongside the diameter of the water mist cooled probe; $\mathrm{s}$ - distance from the edge of the probe 

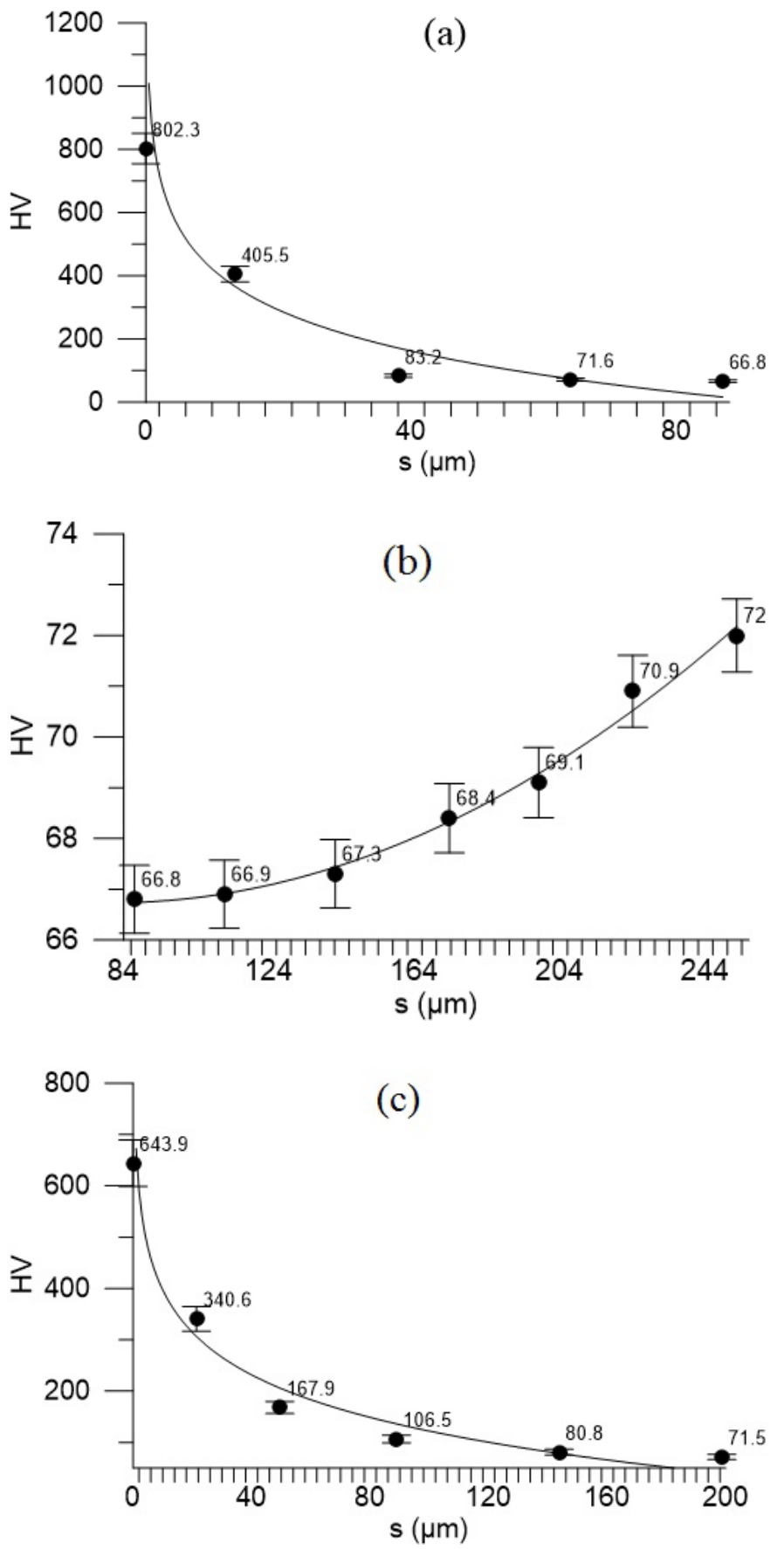

Fig. 10. Hardness around Si pre-eutectic crystal a); b) in uncooled probe; c) in water mist cooled probe; $\mathrm{s}$ - distance from the centre of the crystal

\section{REFERENCES}

[1] R. Władysiak, A. Kozun, Effect of Water Mist Cooling on Microstructure of Hypereutectic Al-Si Alloy, Arch. Foundry Eng. 14, 3, 117-122 (2014).

[2] R. Władysiak, Computer Control the Cooling Process in Permanent Mold Casting of Al-Si Alloy, Arch. Metall. Mater. 58, 3, 10-13 (2013).

[3] H. Yamagata, W. Kasprzak, M. Aniolek, H. Kurita, J.H. Sokolowski, The effect of average cooling rates on the microstructure of the Al-20\% Si high pressure die casting alloy used for monolithic cylinder blocks, J. Mater. Process. Technol. 203, 3, 333-341 (2008).

[4] S.G. Shabestari, M. Malekan, Thermal analysis study of the effect of the cooling rate on the microstructure and solidification parameters of 319 aluminum alloy,Can. Metall. Q. 44, 3, 305-312 (2005).

[5] Z.G. Shen, C. Lü, Experimental tests of investment casting air jet cooling process, Zhuzao/Foundry 63, 6, 567-570, (2014).

[6] R. Władysiak, Effect of water mist on cooling process of casting die and microstructure of alsi11 alloy, Arch. Metall. Mater. 55, 3, 93-9946 (2010)

[7] J. Cho, C. Kim, Al-Si casting alloys in high pressure die casting 8, 1, 49-56, (2014).

[8] S.M.H. Hejazi, F. Majidi, G.H. Akbari, A Cu-Cr alloy with nano and microscale $\mathrm{Cr}$ particles produced in a water-cooled copper mold, Int. J. Miner. Metall. Mater. 17, 5, 629-634 ( 2010).

[9] G. Wang, G. Zhao, X. Wang, Development and evaluation of a new rapid mold heating and cooling method for rapid heat cycle molding, Int. J. Heat Mass Transf. 78, 99-111 (2014),

[10] M. Nowak, O. Golovko, F. Nürnberger, I. Frolov, M. Schaper, Water-Air Spray Cooling of Extruded Profiles: Process Integrated Heat Treatment of the Alloy EN AW-6082, J. Mater. Eng. Perform. 22, 9, 2580-2587 (2013).

[11] J. Kang, X. Hao, G. Nie, H. Long, B. Liu, Intensive riser cooling of castings after solidification, J. Mater. Process. Technol. 215, 278-286 (2015).

[12] C. Rapiejko, B. Pisarek, T. Pacyniak, Effect Of Cr and V Alloy Additions on the Microstructure and Mechanical Properties of Am60 Magnesium Alloy, Arch. Metall. Mater. 59, 2, 10-14 (2014).

[13] L. Heusler and W. Schneider, Influence of alloying elements on the thermal analysis results of Al-Si cast alloys, J. Light Met. 2, 1, 17-26, Feb. (2002).

[14] R.M. Pillai, K.S. Biju Kumar, B.C. Pai, A simple inexpensive technique for enhancing density and mechanical properties of Al-Si alloys, J. Mater. Process. Technol. 146, 3, 338-348 (2004).

[15] R. Xu, L. Li, L. Zhang, B. Zhu, X. Liu, X. Bu, Influence of pressure and surface roughness on the heat transfer efficiency during water spray quenching of 6082 aluminum alloy, J. Mater. Process. Technol. 214, 12, 2877-2883 (2014).

[16] G. Duggan, M. Tong, D.J. Browne, Modelling the creation and destruction of columnar and equiaxed zones during solidification and melting in multi-pass welding of steel, Comput. Mater. Sci. 97, 285-294 (2015)

[17] K. Ghedjati, E. Fleury, M.S. Hamani, M. Benchiheub, K. Bouacha, B. Bolle, Elaboration of AlSi10Mg casting alloys using directional solidification processing, Int. J. Miner. Metall. Mater. 22, 5, 509515 ( 2015).

[18] K.J. Kubiak, T.W. Liskiewicz, T.G. Mathia, Surface morphology in engineering applications: Influence of roughness on sliding and wear in dry fretting, Tribol. Int. 44, 11, 1427-1432 (2011).

[19] H. Yamagata, H. Kurita, M. Aniolek, W. Kasprzak, J.H. Sokolowski, Thermal and metallographic characteristics of the Al-20\% Si high-pressure die-casting alloy for monolithic cylinder blocks, J. Mater. Process. Technol. 199, 1-3, 84-90 (2008). 
[20] H. Kaya, E. Çadırlı, M. Gündüz, Dendritic Growth in an Aluminum-Silicon Alloy, J. Mater. Eng. Perform. 16, 1, 12-21 (2007).

[21] M. Chen, T.Z. Kattamis, Dendrite coarsening during directional solidification of Al-Cu-Mn alloys, Mater. Sci. Eng. A 247, 1-2, 239-247 (1998)

[22] M. Bamberger, I. Minkoff, and M.M. Stupel, Some observations on dendritic arm spacing in Al-Si-Mg and $\mathrm{Al}-\mathrm{Cu}$ alloy chill castings, J. Mater. Sci. 21, 8, 2781-2786 (1986).

[23] B. Karpe, B. Kosec, A. Nagode, M. Bizjak, The influence of Si and $\mathrm{V}$ on the kinetics of phase transformation and microstructure of rapidly solidified Al-Fe-Zr alloys, J. Min. Metall. Sect. B Metall. 49, 1, 83-89 (2013).
[24] N. Raghukiran, R. Kumar, Effect of scandium addition on the microstructure, mechanical and wear properties of the spray formed hypereutectic aluminum-silicon alloys, Mater. Sci. Eng. A. 641, 0, 138-147 (2015).

[25] X. Zhu, R. Wang, J. Peng, C. Peng, Microstructure evolution of spray-formed hypereutectic Al-Si alloys in semisolid reheating process, Trans. Nonferrous Met. Soc. China 24, 6, 1766-1772 (2014).

[26] O. Uzun, T. Karaaslan, M. Gogebakan, M. Keskin, Hardness and microstructural characteristics of rapidly solidified Al-8-16 wt.\% $\% \mathrm{Si}$ alloys, J. Alloys Compd. 376, 1-2, 149-157 ( 2004).

[27] H. Jones, Cooling rates during rapid solidification from a chill surface, Mater. Lett. 26, 3, 133-136 (1996). 